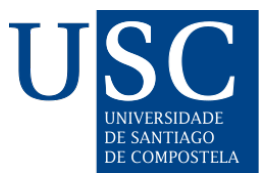

\title{
ÁMBITOS DE MEJORA PARA LA CULTURA DE DEFENSA Y SU COMUNICACIÓN POLÍTICA EN ESPAÑA
}

Areas of improvement for the defense culture and its political communication in Spain

\author{
Alfonso A. López Rodríguez ${ }^{1, a}$, Serafín González-Quinzán ${ }^{2, b}$ \\ ${ }^{1}$ Universidade de Santiago de Compostela, España \\ ${ }^{2}$ Universidade de Santiago de Compostela, España \\ a josevidal@ufpa.br b serafin.gonzalez.quinzan@usc.es
}

\section{Resumen}

La cultura de Defensa, como política de comunicación, disfruta de un dilatado recorrido. Durante esa etapa ha tenido que afrontar un conjunto de elementos de tipo cultural y estructural que han inhibido una difusión más amplia y más profunda de sus mensajes. De este modo, también, impidiendo una normalización de las políticas de defensa como issues objeto de la opinión pública y la agenda mediática. El objetivo de este estudio es determinar los condicionantes principales y determinar las áreas de mejora que permitan un incremento de la eficacia de las políticas de comunicación en el ámbito de la defensa.

Palabras clave: Cultura de Defensa; comunicación política; análisis de políticas públicas.

\begin{abstract}
Defense culture, as a communication policy, has a long history. During this stage it has had to face a set of cultural and structural elements that have inhibited a wider and deeper dissemination of its messages. In this way, it has also prevented the normalization of defense policies as issues of public opinion and the media agenda. The aim of this study is to determine the main conditioning factors and identify improvement areas to increase the effectiveness of communication policies in the field of defense politics.
\end{abstract}

Keywords: culture of Defense; political communication; public policy analysis.

\section{PRESENTACIÓN}

Con la superación del conflicto bipolar que fue la Guerra Fría ${ }^{1}$, en un entorno de rápidos y profundos cambios, casi mutaciones, de los planteamientos estratégicos globales, el Ministerio de Defensa $^{2}$ decidió emprender el inicio de una línea de política aún vigente: la Cultura de Defensa ${ }^{3}$. Esta línea de actuación del MINISDEF supera las dos décadas; durante las que ha encontrado no 
pocas dificultades a lo largo del tiempo. Dentro de los objetivos originarios de esta política, cabe destacar la búsqueda de una mayor comprensión de la labor de la actividad de dicho Ministerio además del conocimiento y reconocimiento de la labor de las Fuerzas Armadas ${ }^{4}$. Sin embargo, a pesar del período de tiempo transcurrido, se mantiene un divorcio entre la sociedad española y las FAS; donde parece dominar el desapego y la indiferencia. Esto ocurre dentro de ese contexto tan particular como lo es la cultura política española.

Este resultado, tras más de 20 años de implementación, es el motivo principal que impulsa el presente estudio, el cual pretende identificar los principales factores, de naturaleza estructural, que afectan a la CD. En especial en los ámbitos de su difusión como en el arraigo y eficacia de dicha política. Dado que los citados ámbitos son clave para la normalización de las cuestiones o issues de defensa como un elemento más del debate y la opinión pública. Esto resulta particularmente importante porque la CD presenta una escasa extensión social y presencia mediática. Elemento especialmente relevante en comparación con los países de nuestro entorno inmediato (Conde de Arjona, 2011) esto es, la Unión Europea. Por lo tanto, la CD implementada por el MINISDEF será el objeto central de estas páginas. Siendo ésta una línea de actividad que, a día de hoy, como se ha señalado, dista de haber alcanzado los objetivos propuestos en la $\mathrm{DDN}^{5}$ de 1996 . Esto ocurre a pesar de ser un elemento estratégico en términos de comunicación política, en especial en el contexto actual, dominado por las redes sociales para un número creciente de ciudadanos.

\section{CONTEXTO GLOBAL, OBJETIVOSO DE ESTUDIO Y MÉTODO DE ANÁLISIS}

El giro copernicano que supuso el fin del conflicto bipolar entre la URSS y los USA a finales del siglo XX y que había protagonizado (casi monopolizado) las relaciones internacionales y las políticas de defensa durante casi medio siglo influye de lleno en la realineación de las políticas de este ámbito en España. Se da una mutación de las necesidades y exigencias de un país miembro de la OTAN dentro de un nuevo escenario internacional y crecientemente globalizado. El resultado fue un auténtico cambio de paradigma en el que se produce una transformación mayúscula de las necesidades militares. Se produce un replanteamiento de las alianzas y alineamientos internacionales; con ello de las exigencias, obligaciones y compromisos de nuestro país en el ámbito de la seguridad y la defensa. El aumento de las misiones en el exterior (principalmente en el teatro exyugoslavo) generó un efecto de arrastre hacia la profesionalización y modernización de las FAS, operando como un factor exógeno en este sentido.

Dentro de nuestras fronteras, esto tuvo varios efectos relevantes que se influyen de manera recíproca. De este modo, un impulso a la profesionalización de las FAS, dada la presión del cambio paradigmático, en un momento de creciente rechazo al servicio militar obligatorio, con el $\mathrm{MOC}^{6}$ como movimiento social y actor relevante del proceso (Martí y Ubasart, 2018). El rechazo al modelo de servicio militar de recluta terminó forjando un movimiento social activo y con visibilidad social (Ordás, 2016). Ambos fenómenos provocaron la aceleración de la citada profesionalización.

Asimismo, el avance de la implantación de las nuevas tecnologías exigió que la CD se adaptase en búsqueda de alcanzar una efectiva comunicación política (Canel, 2006). En el contexto de un profundo cambio tecnológico que se acelera a finales del último decenio del siglo XX al que España no ha sido ajeno (Rúas Araujo y Casero-Ripollés, 2018). En el presente las estrategias 
de comunicación política deben adaptarse al marco más dinámico de las redes sociales como mecanismo para alcanzar a públicos más diversos, se da una multiplicación y diversificación de audiencias, dado que emerge el mundo digital.

Es a partir de este contexto desde el que parte la política de CD. De ahí emergen también los objetivos de este texto, por un lado, encuadrar la política objeto de análisis dentro del concepto, más amplio, de cultura política. Por otro, establecer una imagen de su evolución y situación actual, haciendo especial hincapié en aquellos factores que funcionan como inhibidores de los objetivos buscados por la política de CD.

Por último, se pretende identificar unos ámbitos de mejora vinculados a la esfera de las estrategias de comunicación política e institucional, que resultan claves en el contexto contemporáneo donde dominan las nuevas tecnologías de la información y la comunicación. Factor de alta relevancia por su exigencia de una adaptación (sino mutación) de las prácticas tradicionales en la comunicación institucional corporativa.

En cuanto al método adoptado en este trabajo, dada su naturaleza y alcance limitados por el espacio del mismo se ha optado por una estrategia propia de los estudios de caso (Gerring, 2009). Es este tipo de método resulta clave la revisión de la literatura disponible sobre el tema y los datos y fuentes secundarias. Atendiendo a que sean valiosas y significativas según los criterios de relevancia y pertinencia, en relación al propio objeto de estudio. Además, se contemplan aquellas contribuciones, teorías o enfoques, que, si bien tangenciales, pueden ayudar a comprender mejor la lógica de los procesos que se pretenden comprender y describir en relación a la política objeto de análisis.

\section{DE LA CULTURA POLÍTICA A LA CULTURA DE DEFENSA}

Una manera de abordar la problemática objeto de estas páginas, es comenzar por describir la idea de cultura política. Los estudios sobre el tema tienden, en su versión mayoritaria, a seguir lo ya establecido por Almond y Verba (1966). De este modo, la cultura política es entendida como una orientación particular (de índole psicológica) que mantienen los ciudadanos hacia los objetos políticos dentro de una sociedad concreta (Magre y Martínez, 2015). Para el caso que se analiza, resulta especialmente relevante la faceta afectivo-cognitiva, porque es ésta la que tiene un papel clave en la construcción de la cultura política. Resulta igualmente interesante indicar la relevancia de factores ambientales-coyunturales, que también afectan a la configuración de estos elementos como se verá más adelante.

Para entender la cultura política de un país en concreto es importante conocer el papel de la subjetividad y las actitudes hacia los objetos políticos que la constituyen. En el caso de nuestro país, no es ningún secreto que tanto las FAS, como la política que desarrolla el MINISDEF, son en sí mismo objetos políticos de pleno derecho. Además de ser símbolos de la propia soberanía del Estado. Sin embargo, su alienación respecto de la ciudadanía puede no obedecer a su rango de relevancia; si no a su propio desarrollo histórico en las etapas preconstitucionales ${ }^{7}$.

Como indican Vallés y Martí (2015: 265) las orientaciones hacia los objetos políticos son de cuatro signos diferentes: cognitivas, afectivas, valorativas y conativas. El primer grupo (cognitivas) se centra en el conocimiento, en tanto que las segundas (afectivas) son las que inciden en el ámbito emocional del sujeto. Esta segunda categoría es el estadio donde se forjan las potenciales adhesiones, rechazos o indiferencias, respecto a un objeto político determinado. Por el contrario, 
las dos últimas categorías (orientaciones valorativas y conativas) funcionan de modo distinto. Fundamentalmente porque son una proyección hacia el exterior de las posiciones del individuo. Tanto la valoración, como la intención, son ámbitos de contenido social/grupal donde el individuo va a manifestar una opinión o a realizar una acción. Serían ejemplos de esto últimos actos como el de firmar una petición o acudir a una manifestación. Incluso, aquellas que tienen su proyección en el ámbito digital, tal sería el caso de compartir una información o noticia en una red social, o manifestar la propia opinión en ese tipo de redes. Esto tiene relevancia en tanto que las actividades en este tipo de espacios digitales se mantienen en el tiempo accesibles a otros usuarios.

De acuerdo a la lógica que el modelo de cultura política ha formulado (Vallés y Martí, 2015) la constitución de una CD debería emprender una estrategia centrada en la comunicación (ámbito cognitivo) que comience el proceso. La ciudadanía debe ser consciente de que existe una labor de las FAS y unas actividades del MINISDEF, es un conocimiento que necesita de una adecuada difusión. Conocer la actividad y las medidas que realizan estas instituciones provoca la toma de conciencia (y también la legitimización) sobre el objeto político mismo. A partir de ese instante, ya es probable que se comiencen a crear elementos de tipo afectivo hacia el objeto. El verdadero reto para la CD, en el caso de nuestro país, viene dado por la necesidad de supera unos inhibidores estructurales.

En este sentido, la implementación de la CD ha presentado, históricamente unas particularidades como son su vinculación al ámbito securitario ${ }^{8}$ (Bernal, 2011:25), de modo que en España hablamos de Cultura de Seguridad y Defensa. Por otro, afrontar la acuciante labor de difusión para elevar el conocimiento general del objeto político mismo, así como el incremento de la familiaridad con él. Esto se hace desde las publicaciones de difusión sobre las acciones de las FAS, hasta aquellas que se refieren a las jornadas de puertas abiertas, seminarios etc. Todo ello con la finalidad de influir en los ámbitos tanto cognitivo como afectivo.

La lógica dentro del concepto de cultura política pretende operar sobre las cuatro vertientes de las orientaciones políticas. En ella se aprecia una lógica subyacente: que un mayor conocimiento y comprensión del objeto llevan a una mayor familiaridad, que facilita una orientación afectiva positiva. De este modo las manifestaciones de tipo valorativo tenderán a aparecer con mayor frecuencia y ser más fundamentadas, terminando por incrementar la sensación de eficacia política subjetiva en el ámbito de las intenciones. Es, en suma, la lógica de un círculo virtuoso.

De este modo, la lógica de la acción de la política de CD, en su sentido ideal, se basa en los cuatro puntos indicados por Bernal (2011) que sistematizan lo expuesto en las formulaciones originales de la propia política. Como primer elemento: la divulgación, es esencialmente de naturaleza institucional, está directamente realizada por actividades desde el MINISDEF como desde los medios de comunicación. Esta primera etapa implica la difusión de informaciones, consideradas esenciales, para la expansión y arraigo de la CD. Por el contrario, la segunda fase viene determinado por el conocimiento y comprensión, aquí la participación del ciudadano individual con los medios de difusión es lo más relevante, en una doble vertiente. La primera, conocer la existencia de esa información y: la segunda, comprender la información misma como paso necesario para acceder al tercer nivel del ciclo. Este estadio se alcanza al comprender y aceptar (en el sentido de interiorizar) los conocimientos implícitos en las informaciones sobre defensa, permitiendo emerger una capacidad crítica para evaluar esos temas al poseer lo conocimientos y utillajes conceptuales necesarios. Cabe resaltar que en esta etapa el concepto de acuerdo no implica consenso o adhesión, más bien implica aceptar la legitimidad de la política de Defensa y la actividad de los actores vinculados a ella. Como etapa final está, la ya comentada del compromiso, que supone el mayor 
nivel de comprensión, dado que además de la disposición de conocimiento, implica la capacidad de aplicación de juicio crítico por parte del ciudadano en los temas relacionado con la defensa. En este caso, serían temas que van desde materias relacionadas con el presupuesto militar a las potenciales amenazas que, como sociedad, se deben afrontar. Existe un matiz importante que distingue este estadio del anterior. Si bien en el tercero (aceptación y acuerdo), el ejercicio es puramente individual e intelectual, el cuarto (compromiso) es reflexivo y social, ya que implica el comienzo de la articulación de un discurso y unas posiciones fundamentadas en material de defensa. El objetivo final es una retroalimentación del propio circuito con el resultado de la normalización de las cuestiones de defensa como issue ordinario dentro del debate público y la agenda de medios.

\section{LA CULTURA DE DEFENSA EN ESPAÑA FRENTE A SUS INHIBIDORES}

En el caso de nuestro país se han destacado varios elementos de su cultura política que descuellan respecto a los demás países de nuestro entorno. Por un lado, un elevado grado de lo que se ha llamado cinismo democrático (Jiménez y Villoria, 2008:181) con una bajísima sensación de eficacia política individual vinculada a una profunda insatisfacción política (Magre, 2018). España es un país con una escasa participación en lo que Putnam (2002) denomina organizaciones voluntarias (que él mismo considera fundamentales para una cultura cívica fuerte). Asimismo, la ciudadanía española muestra un elevado grado de desapego y desconfianza, tanto por los partidos políticos como por la figura del político profesional, en unas cotas superiores a las medias europeas (Magre y Martínez, 2015). Este cinismo democrático ${ }^{9}$ es lo suficientemente fuerte como para manifestarse estructuralmente en los estudios de opinión, tanto oficiales como académicos ${ }^{10}$.

En primer lugar, es necesario indicar (Conde de Arjona, 2011) que el nivel de conocimiento por parte de la opinión pública sobre la CD o la actividad del MINISDEF es inferior al de los países de nuestro entorno. En la citada DDN de 1996 ya se conocían estas dificultades y carencias, por lo que se establecieron objetivos como el incremento del conocimiento ciudadano de las labores y actividades de Defensa. La voluntad de esta estrategia es que una mayor difusión/comprensión genere un compromiso basado en el conocimiento y el reconocimiento de estas actividades. En especial, en lo relativo a lo que afecta a la seguridad colectiva del país. Este inicio de la CD se inscribe, como se ha dicho, en un contexto de fin de la Guerra Fría y la emergencia de un nuevo marco estratégico global. La presión hacia el cambio fue un catalizador para que desde el MINISDEF se considerase adecuado emprender una política como la CD dado que era un contexto de profundas mutaciones en el contexto internacional que tendían a incrementar la presencia y la actividad de nuestro país en misiones en el exterior, además de que por aquellos años el movimiento de los insumisos estaba en pleno auge, actuando, en cierta manera, como factor endógeno para el proceso de profesionalización y modernización de las FAS. De esta situación de partida, el elemento clave las estrategias de comunicación de la $\mathrm{CD}$ es el en el último elemento. Éste implica un alto grado de escepticismo y sospecha de una parte sustantiva de la sociedad española hacia la FAS, como se desarrolla a continuación.

Como se ha indicadao, es durante la década de los 90 cuando tiene su máxima expansión el movimiento de insumisión ante el servicio militar obligatorio (Martí y Ubasart, 2018), elemento que operó, como se ha indicado, funcionado de factor endógeno hacia la profesionalización. Este hecho ha de sumarse el de la muy extendida filosofía del "pacifismo ingenuo" (Marina Torres, 2011:69); 
que, a pesar de sus buenas intenciones ${ }^{11}$, supone un obstáculo para la difusión y arraigo de una CD eficaz dentro de la ciudadanía, especialmente porque opera como un inhibidor emocional.

En años recientes (Magre y Martínez, 2015) la cultura política de nuestro país ha ido acentuando su ya tradicional desafección y desconfianza institucional. Uno de los motivos principales tiene su origen en la gran recesión de 2008 que afecto a nuestro país y la ulterior gestión de la misma; cuyos efectos alcanzan el momento presente. Esto implica un escenario nada sencillo para la construcción de las relaciones entre FAS y la ciudadanía mediante la CD. En especial en un contexto de restricción presupuestaria dura (Kornai, 1993) de las finanzas públicas, donde los gastos en Defensa son vistos con suspicacia por gran parte de la ciudadanía, especial en un contexto de devaluación interna, con sus elevados costes sociales (Álvarez, Uxó y Febrero, 2019). Se produce una situación donde cunde un estado de opinión que valora las inversiones en defensa como un gasto suntuario, poco útil frente a las necesidades sociales emergidas como consecuencia de la crisis económica, que se ven empeoradas en la actual crisis del covid-19.

Por otro lado, se ha ido consolidado la idea, ya enunciada por Baqués (2004), de la expansión dentro de la sociedad civil de la idea de que los valores militares son escasamente compatible con los hegemónicos en las sociedades contemporáneas. Este hecho tendría como resultado una separación dentro de la propia sociedad entre los profesionales militares y el resto de ciudadanos. Este fenómeno no es algo exclusivo de nuestro país, donde se aprecia esa idea de sociedades paralelas nunca bien integradas. En España, se da una situación en la que una mayoría de la ciudadanía aun sostiene estereotipos sobre la profesión militar propios del siglo pasado, efecto este que, de modo más atenuado, se reproduce para las FFCCSE ${ }^{12}$.

En este sentido, resulta valioso ver que las propias FAS, como las ya citadas FFCCSE, no son actores unitarios, al igual que pasa con los propios partidos políticos (Katz y Mair, 1993). La institución militar cuenta con miembros más proclives que otros a la apertura y la modernización de la propia institución, frente a otros que consideran la existencia de un ethos propio que ha de conservase (Baqués, 2004; Bernete, 2003). La primera postura sería la más proclive a asumir el proceso de "normalización" de las FAS dentro de la sociedad española. Por desgracia, eso es un debate que supera el ámbito de este texto. Pero no deja de ser relevante apuntar a esa realidad no homogénea de las propias FAS como un hecho sociológico a tener en cuenta.

Otro fenómeno distintivo de la cultura política española, en relación con la Defensa, ha sido la conformación de una "contracultura" en ese ámbito que fue aquilatándose durante la etapa democrática iniciada en 1978, aunque ya aparece dentro del régimen dictatorial anterior (Martí y Ubasart, 2018). Esta contracultura funcionaría como un competidor de la CD, provocaría interferencias en la labor de ésta como mecanismo "civilinizador" (Baqués, 2004) ${ }^{13}$ de las FAS dentro de la sociedad actual y como factor que incrementaría la cohesión social.

Como ya se ha apuntado, dentro de la cultura política española se aprecia una profunda insatisfacción con los políticos y el rendimiento del sistema político en general (Magre, 2018); el resultado lógico es un desapego estructural respecto a las instituciones del estado, especialmente de aquellas con mayor contenido político, aunque las FAS no son ajenas a este fenómeno. Asimismo, cabe señalar que en lo referente a las FAS existe un factor de aislamiento social ya indicado (Baqués, 2004) que atañe a los propios militares en su profesión, tanto por apreciar una ética distintiva en su profesión como por la propia estructuración de la misma. El modelo profesión militar tal como está planteado, implica altos niveles de rotación (Escarda, Agudo y Pérez, 2018) lo que se traduce necesariamente en una falta de arraigo geográfico y humano. Esto impide un incremento 
de la familiaridad y normalización de los miembros de las FAS con la sociedad de su entorno. En este sentido ahonda Bernete (2003) al indicar una serie de elementos que dividen a las FAS de la sociedad actual, por un lado, la deficitaria CD dentro de nuestra sociedad, tanto como el mantenimiento de determinados estereotipos que perviven desde la dictadura (Mellón, 2018). Pero también señala otros de índole material, como son la consideración social de la profesión militar como excesivamente sacrificada y mal remunerada.

Un hecho ya apuntado, que merece desarrollarse, es la importancia de la cohesión social, especialmente en un momento de crisis del modelo democrático (Wilkin, 2018; Plattner 2019). Siendo particularmente interesante para este tipo de cohesión el reconocimiento y normalización de las FAS dentro de la sociedad de la que forman parte. Por otro lado, los incrementos de la cohesión social son importantes como bálsamo contra el profundo y creciente desapego hacia la política que está presente en nuestra sociedad. También como garante de la gobernabilidad (y viabilidad) de nuestro sistema político a largo plazo. La definición de cohesión social de Miguélez y Prieto (2001) resulta enriquecedora al entenderla como un elemento inherente a la comunidad política, fundamentado en la idea de inclusión. Supone el ofertar al ciudadano oportunidades de progreso social y participación en las decisiones públicas de carácter colectivo y, por ende, político. La cohesión social así concebida es un factor de inclusión y de participación de los componentes de la sociedad dentro del sistema político, que se eleva como marco de convivencia.

De este modo, no puede dejar de verse a la CD como una política, no sólo deseable, si no útil para obtener un incremento de la cohesión social por la vía de una ciudadanía ampliada, consciente del valor de los distintos objetos políticos. Para ello es fundamental el papel de la comunicación y a ello se dedica el epígrafe siguiente.

\section{LA CULTURA DE DEFENSA Y LOS POSIBLES ÁMBITOS DE MEJORA EN SU EFICACIA}

Desde los comienzos de la implementación de la CD en la década de los 1990 las formas y tecnologías de la comunicación han cambiado de manera radical, al mismo tiempo que también ha cambiado la propia sociedad a la que se dirige e interpela. En la actualidad, las capacidades de comunicación son mucho mayores y más amplias que en los momentos iniciales de diseño de estas políticas. La revolución de las Tecnologías de la Información y la comunicación ${ }^{14}$ y las Redes sociales ${ }^{15}$ a principios de siglo ha abierto todo un nuevo mundo de oportunidades en términos de comunicación con la ciudadanía. Pero también han surgido nuevas exigencias, el ciudadano, dentro de las redes y comunidades virtuales, ya no se acepta un modelo de comunicación unidireccionalverticalizado. Se ha establecido una exigencia de diálogo, en el que espera que sus posiciones sean tenidas en cuenta, es decir, espera un verdadero feedback. Esta suerte de contrato no escrito se ha dado en llamar paradigma comunicacional de "simetría interactiva" (Túñez-López, CostaSánchez, Míguez González, 2017:923). La irrupción de las TIC, y especialmente las RRSS, como actores relevantes dentro del proceso socializador ha generado un gran impacto, así como todo un nuevo arsenal de estrategias, técnicas y herramientas comunicacionales bien aprovechadas en la esfera política (Campos Domínguez, 2017). Sin embargo, no se pueden soslayar los peligros (Merlos, 2018), desde las fake news a los intentos de manipulación masiva de la opinión pública como el caso de Cambirdge Analytica. No deben olvidarse, además, los grandes cambios en los valores sociales, 
que se venían consolidando desde mediados del pasado siglo, con un mayor hedonismo y una mayor exigencia de inmediatez.

Estos cambios generados por la emergencia de la sociedad de la información (Castells, 1999) han motivado por parte de la Administración del Estado el impulso a un constante acercamiento al ciudadano mediante las TIC. Esta voluntad se manifiesta tanto en la normativa como en la praxis de la electronificación de las administraciones. Esto es así tanto en lo dispuesto e las leyes 39/2015 del 1 de octubre del Procedimiento Administrativo Común de las Administraciones Públicas y la 40/2015 de 1 de octubre, de Régimen Jurídico del Sector Público. Ambas normar han generado un notable impulso en la comunicación digital dentro del procedimiento administrativo. Sin embargo, no dejan de ser muestra patente de que las administraciones han sido receptivas a las demandas de la ciudadanía en este ámbito. Es dentro de esta estrategia amplia de la Administración del Estado donde se inscribe el marco de referencia para el análisis de la acción de la CdeD que, naturalmente, transciende los marcos establecidos por las citadas normas. En realidad, debería establecer un ámbito de comunicación y diálogo con la ciudanía para alcanzar los objetivos de conocimiento y reconocimiento de la labor de FAS, en este sentido se trata de enfatizar en este aspecto el esfuerzo que ya han realizado las administraciones públicas de nuestro país para adaptarse con éxito a los nuevos canales de comunicación en un ámbito tan sensible para el ciudadano como su relación con la Administración.

Pueden identificarse, al menos, tres ámbitos críticos, una vez revisada la literatura sobre la CD. Por un lado, aquellos de índole material que afectarían a temas inmanentes de tipo económico o de seguridad interpersonal (individual y colectiva). Por otro, la esfera de lo afectivo, de las filias y las fobias, también de las indiferencias; un ámbito donde las estrategias de comunicación es un factor crucial. Por último, y en vinculo estrecho con los anteriores, en ámbito comunicacional, aquí entendido como las estrategias y métodos de articular un discurso atractivo y efectivo de cara al receptor.

Comenzando por el último elemento, en lo que se corresponde con la materia de comunicación, a pesar de los notables esfuerzos que se han realizado desde el MINISDEF, puede resultar necesario adoptar un paradigma más proactivo en las redes sociales. En este sentido, se cuenta con el bien documentado éxito de la cuenta oficial de twitter vinculada al $\mathrm{CNP}^{16}$ que ha supuesto un cambio en la forma de comunicación y relación con los ciudadanos desde este tipo de plataformas. Como señala Harguindeguy (2012: 46-47) resulta clave para las políticas públicas el que sus promotores cuenten "buenas historias" para implementar una estrategia discursiva eficaz. En un sentido similar, la comunicación funciona como un activo de la propia organización, de carácter estratégico (Hodge, Anthony y Gales, 2003) que trabaja tanto de manera interna y externa; siendo un elemento clave en los procesos de cambio y relación con el entorno. De acuerdo a este planteamiento, la comunicación corporativa del MINISDEF, que se centre en la $\mathrm{CD}$, ha de fundamentarse en la maximización de los elementos para la gestión de dicho modelo comunicacional, que se resume en tres ámbitos (Apolo, Báez, Pauker, Pasquel, 2017): la identidad, la imagen y la reputación.

En el ámbito de las estrategias de comunicación, al buscarse cajas de resonancia de los mensajes, las RRSS han terminado por imponerse como herramientas de importancia dentro del ámbito de la comunicación política (Ruíz del Olmo y Díaz, 2017:121) teniendo una comunidad activa, amplia y políticamente interesada. De este modo, las RRSS funcionan como amplificador para la comunicación institucional, terminando por erigirse en una herramienta estratégica dentro del ámbito comunicativo y relacional. En lo que concierne a Twitter, Campos Domínguez (2017) señala 
varios hechos relevantes. Por un lado, la normalización que se ha hecho como herramienta de comunicación por parte de los partidos políticos. Por otro, su relativa ambivalencia, dado que para algunas campañas han funcionado como elementos de movilización y debate y otras como un ámbito de conflicto y viralización ${ }^{17}$.

La ambivalencia de las RRSS, como factor de retroalimentación positivo o negativo, tiene que ver con el cambio del perfil de usuario y la misma lógica y funcionamiento del medio. En este caso, prima la interacción y la simultaneidad/instantaneidad como categorías prevalentes. Es un modelo de comunicación donde el perfil de usuario varia respecto a los medios de comunicación tradicionales, especialmente por su proactividad y la existencia de la ya señalada "simetría interactiva" ${ }^{18}$ (TúñezLópez, et al, 2017). Esto exige una gestión de comunidades y una dirección de comunicación particularmente hábil para este tipo de modelo comunicacional, que no es unidireccional si no interactivo y en red.

Sin embargo, no hay que perder de vista la existencia de inconvenientes (Alonso González, 2016) como el "gap digital". Una gran mayoría de la población aún no es usuaria activa de ese tipo de RRSS, lo cual puede sesgar tanto la comunicación como los resultados, en especial en un país con un acusado envejecimiento de la población como es nuestro caso.

Teniendo presente este hecho, resulta más que adecuado adoptar la estrategia combinada que emerge del estudio de Túñez-López et.al (2017) donde se indica que las herramientas de las RRSS se mantienen en paralelo con la comunicación audiovisual tradicional (radio, televisión y prensa escrita) modelo que resulta coherente para la estrategia de comunicación de la CD por dos motivos fundamentales. El primero sería maximizar la eficacia y el impacto por la sinergia de medios. El segundo motivo (quizá más relevante), la naturaleza pública del MINISDEF y la CdeD como patrimonio ciudadano que se incardina en una lógica inclusiva que buscan las administraciones públicas españolas con la ciudadanía.

En este sentido, es un hecho que dentro de la opinión pública española no existe un elevado sentimiento de amenaza ni de inseguridad en materia militar. Esto se debe a que la Defensa, al igual que la Seguridad Pública, son, en sí, un bien público paradójico. Por un lado, resulta probada su naturaleza de bien público (Stiglitz y Rosengard, 2016), sin embargo, su provisión eficiente "invisibiliza" las amenazas. Esto implica que el consumidor (en este caso la ciudadanía) no presione por una mayor inversión en el bien, sino más bien lo contrario. El motivo más probable puede ser el desconocimiento de las amenazas, dada la escasa extensión de la CD. Aquí entramos en el ámbito de lo emocional, un conocimiento de las actividades de las FAS (y de las FFCCSE FCS) implica, tanto la toma de conciencia de las amenazas, como de reconocimiento de la labor de estos colectivos para evitarlas y mantener tanto nuestra seguridad individual como colectiva.

Por otro lado (pensando en los efectos de una comunicación a corto plazo) mientras que la preocupación por las potenciales amenazas es baja, la preocupación por el empleo es alta y los problemas de índole económica son sistemáticamente los más elevados en los estudios y barómetros del CIS. Históricamente, el paro ha sido el primer problema sentido por los españoles. Es aquí donde la actividad industrial del MINISDEF puede ser un potente difusor de la CD. En este caso, la dinámica de la entrada en agenda y la expansión de la CD implica una estrategia comunicativa que no vaya por presentar a la Defensa como un problema, que es la forma de presentación clásica de los temas (Subirats, et. al.,2015) si no como una potencial solución de otros, como una oportunidad. 
Cabe señalar que, desde el fin de la burbuja inmobiliaria, el sector exportador vinculado a la Defensa ha experimentado un notable crecimiento de las exportaciones. Es, además, un núcleo de actividad donde el I+D+i es fundamental, pudiendo ser, en casos, intensivo en este insumo. Eso hace de la política industrial de Defensa un sector estratégico no sólo para satisfacer las propias necesidades de la defensa nacional, si no para la economía en general. De modo que la inversión en Defensa lo es también, en parte, en I+D.

Este factor es, en el contexto socioeconómico actual, un elemento relevante. Especialmente dentro del contexto de una IV revolución industrial, que abre un contexto disruptivo (Schwab, 2015) en el que cambian los sistemas de producción, gestión e incluso gobierno. Se está produciendo un uso masivo de las TIC y la inteligencia artificial y la gestión, proceso y minería de datos. Puede añadirse que esa misma disrupción tecnológica está cambiando los planteamientos estratégicos de las fuerzas armadas en el escenario global.

Este nuevo contexto global, que afecta de modo profundo, no ya a las relaciones de producción, si no a la misma naturaleza y función de los Estados, pueden definirse como el que está ya presente en "los actuales sistemas ciberfísicos que recopilan y procesan información, toman decisiones inteligentes y ejecutan tareas en entornos cambiantes" (Joyanes Aguilar, 2017:24). De manera que son las nuevas industrias $4.0^{19}$ dentro de las que destacan aquellas que añaden a productos de consumo (desde los televisores a los automóviles) una interconexión digital global (o internet de las cosas) las que suponen un desafío tecnológico disruptivo que se debe afrontar. Es un nuevo paradigma de producción, consumo y gestión de la información donde elementos como el Big Data, la inteligencia artificial y la ciberseguridad son fundamentales para afrontar los nuevos desafíos socioeconómicos con éxito. Es en el ámbito de la seguridad donde la CD debe influir como mecanismo para captar la atención de los públicos ciudadanos.

Por otro lado, dentro de ese nuevo paradigma emergente es necesario mantener la cohesión social. En este sentido Alfonso Merlos (2018) habla del fomento de los intereses nacionales, dentro de ellos, de lo que él entiende como los mimbres de un proyecto compartido. Esa es la idea de la cohesión social que brinda una CD arraigada y un sector industrial que no se desengancha de las disrupciones tecnológicas, tanto por razones económicas como de seguridad nacional. Las cifras (Gonzalvo Navarro, 2016) hablan de más de 800 sociedades con una facturación que ya ronda el $1 \%$ del PIB nacional, puede parecer una cifra escasa, pero en términos absolutos puede superar los 10.000 millones de euros, siendo uno de los pocos sectores industriales en expansión.

En conexión con lo anterior, hay que comunicar a la ciudadanía las oportunidades que brinda la inversión en la defensa como un nicho de oportunidades económicas. Como indica Carrasco Gallego (2011) existe diversos análisis sobre el impacto del gasto en defensa y el crecimiento económico. En general parece que para nuestro país está siendo positivo si nos atenemos a los análisis más rigurosos. En relación con esto, la idea más prometedora en términos económicos y también sociales, es la que genera un efecto de arrastre (Carrasco Gallego, 2011), ya no de crecimiento, sino de sinergia con el sector industrial civil. Es relevante no olvidar la importancia de las connotaciones materiales del bienestar, dado que los valores materialistas han experimentado un incremento en su importancia (Polavieja, 2013) en los últimos años, es especial por el impacto de la crisis de 2008, centrado en la idea de seguridad material y bienestar económico.

Para dar a conocer estas cifras y el contexto, dentro de una política de comunicación eficaz, hay que indicar que un sector industrial no sólo implica una oportunidad económica directa (el empleo), sino también un efecto indirecto, la sinergia que implica el crecimiento, pero también el desarrollo 
que genera la inversión en I+D y en la aplicación de tecnología a la producción. La vinculación del interés material directo e indirecto de los ciudadanos con la actividad del MINISDEF y el sector de defensa es un elemento que puede servir de palanca para la expansión de la CdeD en la sociedad. Esto es especialmente cierto si los avances tecnológicos del sector tienen una proyección en la vida civil, en este caso, la experiencia estadounidense con la carrera aeroespacial y la aplicación de sus descubrimientos e innovaciones a la vida civil resulta paradigmática.

En resumen, como cierre de esta sección, puede entenderse que el objetivo de operar sobre los tres factores citados pretende culminar un proceso de "civilinización" (Baqués, 2004:128) de las FAS en la sociedad española en la que exista, no ya una convergencia entre valores civiles y militares, sino también una apertura social y profesional de las propias FAS. El objetivo es la normalización plena de las mismas dentro de la sociedad democrática contemporánea, siendo así un corolario de esa normalización el arraigo de la CD como un elemento del debate dentro de la opinión pública, obteniendo las políticas de Defensa un estatus similar al de otras áreas como la sanidad y la educación, este protagonismo es además positivo en términos de accountabilty pública (Juárez, Romeu y Pineda, 2016; Ríos y Garro, 2017), un indicador del grado de madurez de un sistema democrático contemporáneo.

\section{CONCLUSIONES}

El presente texto ha tenido la voluntad de reivindicar no sólo la CD como un instrumento para acercar las políticas de Defensa a la opinión pública, si no, también, una pieza más en el puzle de la construcción de una ciudadanía completa e integral. De este modo, contribuyendo a normalizar las FAS y su actividad como un elemento más de la cultura política.

A partir de dicha voluntad se han señalado las líneas de acción que componen la, ya veterana, política de CD en España, para, seguidamente indicar los factores de inhibición más sobresalientes que dificultan una difusión y arraigo significativos. Dichos elementos, pues, reducen drásticamente la eficacia potencia de la CD.

Como factores que han aparecido como clave, dentro del contexto actual, se centran en la implementación de líneas de comunicación de naturaleza dinámica y proactiva en el espacio digital, en particular dentro de las RRSS. De este modo, expandir a todo el ámbito digital la necesaria labor de concienciar de las amenazas y riesgos que afrontamos como sociedad; a la par que forjando vínculos de tipo emocional y afectivo de signo preferentemente positivo.

Asimismo, un elemento que cabe destacar por su potencial, en especial dentro de la gran incertidumbre socioeconómica que ha dejado la pandemia del COVID-19, está en la esfera de los intereses materiales. Las FAS no sólo son protectores frente al desastre, como el caso de las acciones de la UME, si no que engloba un sector productivo tecnológicamente avanzado y con un potencial a la hora de contribuir a un desarrollo colectivo.

Por último, se aprecia que los citados elementos dentro de una comunicación adaptada a las nuevas practicas y tecnologías ayudará a superar los tradicionales inhibidores para la política de CD. Todo lo anterior contribuye de manera exitosa a normalizar tanto la actividad de las FAS como de las tareas que realiza el MINISDEF en la actualidad. De este modo, se constituye una cultura política más amplia y, por ende, una ciudadanía más completa. 


\section{BIBLIOGRAFÍA}

ALMOND, G. y VERBA, S. (1966). The civic culture: political attitudes and democracy in five nations. Princeton: Princeton University Press.

ALONSO GONZÁLEZ, M. (2016). Opinión pública y web 2.0. Las redes digitalizan el barómetro político en España. Revista Mexicana de Opinión Pública, Julio-diciembre, 95-113.

ÁLVAREZ, I., UXÓ, J. y FEBRERO, E. (2019). Internal devaluation in a wage-led economy: the case of Spain. Cambridge Journal of Economics, 43(2), 335-360. DOI: https://doi.org/10.1093/cje/bey027

APOLO, D., BÁEZ, V., PAUKER, L. Y PASQUEL, G. (2017). Gestión de la comunicación corporativa: consideraciones para el abordaje de su estudio y práctica. Revista Latina de Comunicación Social, 72, 521-539.

BAQUÉS, J. (2004). La profesión y los valores militares en España. En Revista Internacional de Sociología, 38, 127-146.

BAQUÉS, J. (2015). Estado y sistema político. En M. Caminal y X. Torrens (eds.) Manual de ciencia política (pp.39-70). Madrid: Tecnos.

BERNAL, P. (2011) La cultura de seguridad y defensa en España. Sus orígenes y evolución. Cuadernos de Estrategia,155,23-54.

BERNETE, F. (2003). Ejército profesional y distanciamiento civil de la Defensa. Papers, revista de sociología, 69, 83-100.

CAMPOS DOMÍNGUEZ, E. (2017). Twitter y la comunicación política. El profesional de la información, 26(5),785-793. DOI: https://doi.org/10.3145/epi.2017.sep.01

CANEL, M. J. (2006). Comunicación política. Madrid, Tecnos.

CARRASCO GALLEGO, J.A. (2011). Crecimiento económico y gasto en defensa. Revista IEEE, 48. Recuperado de: http://www.ieee.es/temas/seguridad-y-defensa/2011/DIEEE048_2011GastoDefensa.html

CONDE DE ARJONA, J. (2011). La cultura de seguridad y defensa en los países de nuestro entorno. Cuadernos de Estrategia, 155, 103-140.

CASTELLS, M. (1999). La era de la información: economía, sociedad y cultura. Alianza, Madrid.

GERRING, J. (2009). The Case Study. What It Is and What It Does. En Political Science (pp. 1133-1165). Nueva York: Oxford University Press.

GÓMEZ ESCARDA, M, AGUDO ARROYO, Y. Y PÉREZ REDONDO, R.J. (2018). El modelo living apart toguether (LAT) y el modelo cohabitante en las Fuerzas Armadas Españolas. EMPIRIA: Revista de Metodología de Ciencias Sociales, 41,57-78.

GONZALVO NAVARRO, V. (2016). Inteligencia económica e industria de defensa nacional. En Boletín IEEE, 3, 295-307.

HODGE, B.J., ANTHONY, W.P. Y GALES, L.M. (2003). La teoría de la organización (un enfoque estratégico). Madrid: Pearson.

HARGUINDÉGUY, J-B. (2015). Análisis de políticas públicas. Madrid: Tecnos.

JANOWITZ, M. (1985). Las pautas cambiantes de la autoridad organizativa: la institución Militar. En Bañón, F. y olmeda, J.A. (comps.) La institución militar en el Estado contemporáneo, pp. 81-99.

JIMÉNEZ, F. Y VILLORIA, M. (2008). Percepción social de la corrupción en España. Anuario de la Facultad de Derecho de la Universidad Autónoma de Madrid, 12, 168-183.

JOYANES AGUILAR, L. (2017). Ciberseguridad: la colaboración público-privada en la era de la cuarta revolución industrial (Industria 4.0 versus ciberseguridad 4.0). Cuadernos de Estrategia, 185,19-64. 
JUÁREZ, G., ROMEU, J. Y PINEDA, C. (2016). La acuontability pública: un concepto abierto. Práxis Sociológica, 21, 96-119.

KATZ, R. Y MAIR, P. (1993). The Evolution of Party Organizations In Europe: The Three Faces of Party Organization. En W. Crotty (ed) Political Parties in a Changing Age, American Review of Politics, 14, 593-617.

KORNAI, J. (1993). Market Socialism Revisited. En P. Bardham y J.E. Roemer (eds.) Market Socialism. Nueva York: Oxford University Press.

MAGRE, J (2018). Los principales rasgos de la cultura política de los españoles. En J.M. . Reniu (ed.), Sistema político español (pp. 361-374). Barcelona: Huygens

MAGRE, J. y MARTínEZ, E. (2015). Cultura Política. En M. Caminal y X. Torrens (eds.) Manual de Ciencia Política (pp.441-469). Madrid: Tecnos.

MARINA TORRES, J.A. (2011). Pedagogía de la cultura de seguridad y defensa en la enseñanza no universitaria. Cuadernos de Estrategia,155,66-82.

MARTÍ I PUIG, S. Y UBASART-GONZÁLEZ, G. (2018). Movimientos sociales y protesta política (1978-2018). En J.M. Reniu (ed.), Sistema político español (pp. 361-374). Barcelona: Huygens.

MELLÓN, J.A. (2018). El Franquismo (1936-1975). En J.M. Reniu (ed.), Sistema político español (pp.39-54). Barcelona: Huygens.

MERLOS, A. (2018). Políticas de seguridad en la era de la posverdad. Cuadernos de Estrategia, 197,83-106.

MIGUÉLEZ, F. Y PRIETO, C. (2001). Crisis del empleo y cohesión social. Cuadernos de Relaciones Laborales, $19,223-240$.

ORDÁS, C.A. (2016). No-violencia, objeción de conciencia e insumisión en España 1970-1990. Polis, 15(43), 271-291.

PLATTNER, M.F. (2019). Illiberal democracy and the Struggle on the Right. Journal of Democracy, 31(1), 5-19.

POLAVIEJA, J. (2013). Economic Crisis, Political Legitimacy and Social Cohesión. En Duncan Gallie (ed.) Economic Crisis, Quality of Work and Social Integration: The European Experience, 256-278.

PUTNAM, R. (2002). Solo en la bolera: colapso y resurgimiento de la comunidad norteamericana. Barcelona: Galaxia Gutenberg.

RÍOS RAMÍREZ, A. Y GARRO, J.E. (2017). Acountability y sociedad civil: el control político en la era digital. Papel Político, 22 (2), 311-337.

RÚAS ARAUJO, X. Y CASERO-RIPOLLÉS, A. (2018). Comunicación política en la época de las redes sociales: lo viejo y lo nuevo, y más allá. En: adComunica, 16, 21-24. DOI: http://dx.doi.org/10.6035/2174-099 2.2018.16.

RUIZ DEL OLMO, F.J. Y BUSTOS DÍAZ, J. (2016). Del tweet a la fotografía, la evolución de la comunicación política en Tiwtter hacia la imagen. El caso del debate del estado de la Nación en España (2015). Revista Latina de Comunicación Social, 71, 108-123. DOI: 10.4185/RLCS-2016-1086

SCHWAB, K. (2016) The Fourth Industrial Revolution. Ginebra: World Economic Forum.

STIGLITZ, J y ROSENGARD, J.K. (2016). La economía del sector público. Barcelona: Antoni Bosch.

SUBIRATS, J., KNOEPFEL, P., LARRUE, C. Y VARONE, F. (2012). Análisis y gestión de políticas públicas. Barcelona: Ariel.

TUÑEZ-LÓPEZ, M., COSTA-SÁNCHEZ, C. Y MÍGUEZ GONZÁLEZ, M.I. (2018). Avances y retos de la gestión de la comunicación en el siglo XXI. Procesos, necesidades y carencias en el ámbito institucional. Estudios sobre el Mensaje Político, 24(1), 921-940. DOI http://dx.doi.org/10.5209/ESMP.59987

VALLÉS, J.M. Y MARTÍ, S. (2015). Ciencia Política. Barcelona: Ariel. 
WILKIN, P. (2018). The Rise of Illiberal Democracy: the Orbanization of Hungarian Political Culture. Journal of World-System Research, 24 (1), 5-42.

Notas

1 Siguiendo el preámbulo la Directiva de Defensa Nacional de 1996 se extrae este pasaje donde se explicitan las bases de lo que sería la Cultura de Defensa en España: "[Por último,] el proceso de modernización y mejora de las estructuras nacionales de defensa y de potenciación de las Fuerzas Armadas requiere, como uno de sus elementos más significativos, que la sociedad española comprenda, apoye y se sienta comprometida con la consecución de los objetivos buscados. En este sentido, será preciso afianzar la sintonía entre la sociedad y sus Ejércitos sobre la base de un mejor conocimiento de la realidad militar y de las necesidades y responsabilidades de España en cuanto afecta a su seguridad. Este objetivo lleva implícita la necesidad de hacer que la sociedad española perciba claramente que la protección de su libertad, independencia y prosperidad, la defensa de sus valores, forma de vida, derechos e intereses, así como la salvaguarda de la soberanía, de la integridad territorial y del ordenamiento constitucional demandan una adecuada política de defensa que permita hacer de nuestras Fuerzas Armadas un instrumento eficaz de disuasión, prevención y respuesta. En consecuencia, la sociedad, como parte de su contribución a la tarea común de la defensa, y consciente de las carencias actuales derivadas de las insuficientes dotaciones presupuestarias de los últimos años, dedicará recursos en una cuantía suficiente para la consecución de unas Fuerzas Armadas acordes con el papel que a España le corresponde ejercer." [énfasis en el propio texto]

2 En adelante MINISDEF

3 En adelante CD, se mantiene el enunciado completo para títulos y encabezamientos.

4 En adelante FAS

5 Abreviatura de Directiva de Defensa Nacional

6 Siglas del Movimiento de Objeción de Conciencia que aglutinaba a las personas que no deseaban, por motivos éticos y axiológicos fundamentalmente, prestar el servicio militar obligatorio aún vigente en el país en aquellos momentos.

7 Resulta innegable que dentro del imaginario colectivo de la sociedad española las FAS han estado vinculadas como soporte al régimen borbónico del turnismo, durante los reinados de Alfonso XII (alcanza el poder mediante pronunciamiento militar) y de Alfonso XIII (promociona la etapa dictatorial del general Primo de Rivera). Además de que, durante la dilatada dictadura del general Franco, los miembros provenientes de las FAS supondrían alrededor de un tercio de los ministros del período.

8 Esto vendría a significar, siguiendo al citado autor, que la estrategia de comunicación de la CD se ha centrado en el énfasis de la seguridad de los ciudadanos y la comunidad política, difuminando los elementos militares con una dimensión más netamente castrense. Pero también la faceta de elemento estratégico en íntima vinculación con las relaciones internaciones. De esta manera, se da una visibilidad privilegiada, por ejemplo, a las misiones humanitaria de las FAS o a las acciones de UME; incluso las actividades de los cuerpos policiales o la Guardia Civil.

9 También podríamos citarlo por su "inversa" institucional, el déficit democrático de las instituciones nacidas en el seno de la Constitución de 1978 y que, en muchos casos, no generan la adhesión esperada entre los ciudadanos. Casos relevantes son el de la misma Jefatura del Estado, así como la valoración de instituciones clave como el Poder Judicial, los partidos políticos o los propios políticos en su papel de actor institucional. Con esto la idea que se quiere transmitir es que existen posiciones que entienden que la variable que explica el cinismo democrático es de carácter institucional.

10 En los barómetros realizados por el CIS el ítem "Los/as políticos/as en general, los partidos y la política" dentro de la pregunta “¿Cuál es, a su juicio, el principal problema que existe actualmente en España? ¿Y el segundo? ¿Y el tercero?" ha alcanzado en mayo la segunda posición y se sigue incrementando en los avances de junio y julio de 2019, afectado por la no formación de gobierno tras las elecciones generales del 28 abril del mismo año. Referencia: http://www.cis.es/cis/export/sites/default/-Archivos/Marginales/3240_3259/3247/es3247mar.pdf

11 Una forma breve de definir este tipo de postura es que parten de una buena intención ingenua, deudora de cierto desconocimiento sobre la CD y las relaciones internacionales. Puede sintetizarse en la idea de que la desaparición de los efectivos militares, y del Ejército como institución, provocaría un efecto de desaparición de los conflictos armados. Dentro de una lógica de acuerdo al esquema de "si mi país no posee fuerzas armadas, 
nadie se sentirá amenazado y por tanto no querrán atacarme". Su objetivo es completamente lógico y deseable: un contexto nacional e internacional de paz, seguridad y ausencia de conflictos violentos, que sea, además, permanente. Sin embargo, es, en suma, una forma de entender a las FAS y a las actividades propias de Defensa desde un prisma atávico, como meros elementos de agresión, fuerzas de conquista, ocupación y dominación.

12 Abreviatura oficial para nombra a las Fuerzas y Cuerpos de Seguridad del Estado.

13 Siguiendo al citado Josep Baqués; el concepto se centra en la idea de la normalización del personal que desempeña su actividad profesional dentro de las Fuerzas Armadas. Implica su integración y adaptación a la sociedad civil dentro de un paradigma de normalidad. El proceso supone una convergencia entre valores civiles y militares, siendo los primeros los que influyen en los segundos. El concepto fue alumbrado por Morris Janowitz (1986) como reconocimiento a cambios sociales y actitudinales hacia lo militar en los Estado Unidos.

14 En adelante TIC.

15 En adelante RRSS.

16 Dentro de los medios de comunicación existe un conjunto de noticias que acreditan el éxito de la gestión de comunicación en redes sociales de la persona al cargo del "community manager" de la cuenta @policianacional. Creando un tipo de comunicación con los usuarios proactiva y participativa que generó un amplio feedback dentro de la comunidad de usuarios, con lo que se alcanzaba tanto eficacia en la comunicación como impacto de los mensajes.

17 Debe indicarse que la autora (Campos Domínguez) compara las campañas presidenciales de los USA en la etapa de Obama (elección para su segundo mandato 2012) y la elección de Donald Trump en la campaña de 2016; destacando la divergencia en el uso de las RRSS, en especial Twitter, en ambos comicios.

18 Este tipo de compromiso de comunicación e interacción se centra en aceptar las nuevas normas del medio. En las RRSS se centra en la idea de adoptar la horizontalidad en la comunicación, así como otros elementos como el hecho de las comunicaciones simultáneas e inmediatas, el consumo/producción de contenidos en línea, etc. Para un desarrollo más detallado véase Túñez-López, et.al. (2017).

19 El propio Joyanes (2017) indica que el origen de esa expresión de industria 4.0 que sería la emergencia de la IV revolución industrial nace en Alemania como forma de aludir a la digitalización de sistemas y procesos en la industria y su interconexión global mediante el "internet de las cosas". 